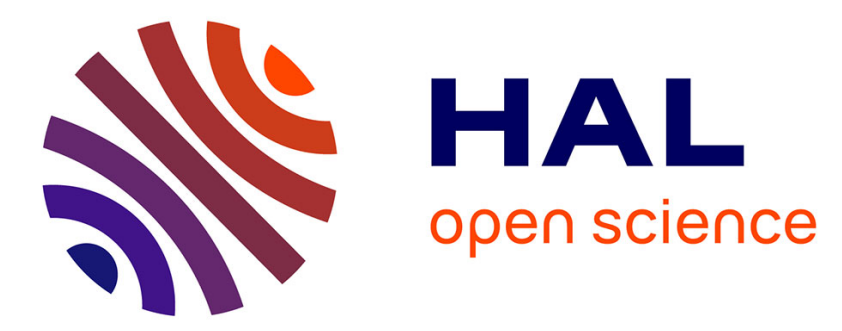

\title{
Experimental observation of induced anisotropy of the Mullins effect in particle-reinforced silicone rubber
}

\author{
Guilherme Machado, Grégory Chagnon, Denis Favier
}

\section{To cite this version:}

Guilherme Machado, Grégory Chagnon, Denis Favier. Experimental observation of induced anisotropy of the Mullins effect in particle-reinforced silicone rubber. SIXTH EUROPEAN CONFERENCE ON CONSTITUTIVE MODELS FOR RUBBER, Sep 2009, Dresde, Germany. pp.511-515. hal-01395960

\author{
HAL Id: hal-01395960 \\ https://hal.science/hal-01395960
}

Submitted on 13 Nov 2016

HAL is a multi-disciplinary open access archive for the deposit and dissemination of scientific research documents, whether they are published or not. The documents may come from teaching and research institutions in France or abroad, or from public or private research centers.
L'archive ouverte pluridisciplinaire HAL, est destinée au dépôt et à la diffusion de documents scientifiques de niveau recherche, publiés ou non, émanant des établissements d'enseignement et de recherche français ou étrangers, des laboratoires publics ou privés.

\section{(c)(1)}

Distributed under a Creative Commons Attribution| 4.0 International License 


\title{
Experimental observation of induced anisotropy of the Mullins effect in particle-reinforced silicone rubber
}

\author{
G. Machado, G. Chagnon \& D. Favier \\ Université de Grenoble/CNRS, Laboratoire 3S-R, Grenoble, France
}

\begin{abstract}
This study is concerned with the experimental observation of anisotropy induced by the Mullins effect in a particle-reinforced silicone rubber. Like many filled rubber-like materials, filled silicone exhibits highly nonlinear mechanical behavior. This nonlinearity is characterized by large strain levels under static conditions, a non-linear stress-strain response and strain rate dependence. However, experimental data concerning the influence of tensile loading cycles in one direction on the stress-softening in other tension directions is quite scarce. In this scope several tension cyclic tests were carried, using a filled silicone rubber material, in order to evidence the anisotropy of the stress-softening phenomenon. The results lead to the conclusion that tensile cycles in one direction practically do not cause the Mullins effect in tension in the perpendicular direction. Nevertheless, the level of influence of the Mullins effect developed in one tension direction on tension behavior for intermediate directions could be measured with respect the different angles in plane. Thus, the anisotropy of the Mullins effect becomes clearly evident.
\end{abstract}

\section{INTRODUCTION}

Like many filled rubber-like materials, as well as soft biological tissues and other biomaterials, filled silicones exhibit highly non-linear mechanical behavior. This non-linearity is commonly characterized by large strain levels under static conditions, a non-linear stress-strain response and strain rate dependence. Finally, under cyclic loading conditions, hysteresis and stress-softening behaviors are observed on both filled and unfilled elastomers. For the last half century all these cyclic phenomena were evidenced and modeled to support the most widely engineering applications. However, their microscopic mechanisms (breaking of weak chains, breaking of links, desabsorption of chains, etc.) explanation remains non-unanimous.

Hysteresis is rather related to the dissipative nature of material, i.e., related with viscoelasticity Bergstrom (2000) and viscoplasticity Miehe (2000) behaviors. It is characterized as the difference between loading and unloading paths during a stabilized cycle. On the other hand the stresssoftening phenomenon, also called the Mullins effect (see Mullins (1969)), can be described as a softer behavior of the second loading after a first loading. It can be idealized as an instantaneous and irreversible softening of the stress-strain curve, due to rearrangements in the microstructure of the material that occurs whenever the load increases beyond its prior all-time maximum stretch value. At times when the load is less than a prior maximum, nonlinear elastic behavior prevails. One time the previous maximum stretch is reached the loading path turns up and follows the primary curve again up to a new maximum.

Through the years, the Mullins effect has experimentally been observed in different deformation states and numerous models have been proposed, but experimental data concerning the influence of loading cycles in one direction on the stresssoftening in other directions are quite scarce.

Mullins (1947) has alluded that the degree of softening was not the same in all directions for natural rubber samples cut both along and perpendicular to the direction of the previous preconditioning stretch; and thus some anisotropic stress-strain properties were developed. This evidence, for example, can be found in a homogeneous plane-strain compression experiment by Pawelski (2001) and in a simple shear experiment performed by Muhr (1999) where simple shear loadings in different directions produce different responses. Other experimental results can be seen in Laraba (2003) using a carbon-black filled natural rubber, Diani (2006) for the commercial elastomer filled black (EPDM) and Itskov (2006) for carbon-black filled acrylate rubber (ACM). All these experimental results point out the strain-induced anisotropy in orthogonal directions due to some in-plane preconditioning test procedure.

Within that context, the aims of this work are to characterize and understand the mechanical behavior of a filled silicone. The objective is to 
focus on the strain-induced anisotropy by studying the influence of loading direction on the Mullins effect.

\section{EXPERIMENTAL SETUP}

\subsection{Preparation of the silicone specimens}

The samples used in the experiments were made of a filled silicone rubber called Rhodorsil ${ }^{\mathbb{R} T} \mathrm{RV} 3428$ supplied as two liquid components: the uncured silicone and the curing agent. The final material is produced by a polyaddition, curing at room temperature. The liquid mixture is injected in a mold to obtain a sheet with constant thickness.

Specimens used for each of the experiments were made using the same protocol of elaboration, in order to obtain specimens with reproducible mechanical properties, as follow: (i) mixing the components with a $10 / 1$ mass ratio, (ii) putting the mixture under vacuum for 20 minutes in order to eliminate undesirable entrapped air bubbles, (iii) sheet molding injection, (iv) putting mold inside an oven at $70^{\circ} \mathrm{C}$ for 4 hours in order to accelerate the curing process and assure a sufficient crosslinking density; (v) sheet demolding after 1 hour exposed at ambient temperature.

Finally, the external surface of the molded plate was coated with a stochastic silicone paint pattern. Made of small speckles, the pattern is necessary for the digital image correlation (DIC) field measurement. Note that the quality of the coated pattern (size, density and gray contrast level) is a critical point to obtain an accurate strain field measurement.

\subsection{Testing procedures}

All the quasi-static experiments were conducted on a MTS 4M universal testing machine with an Entran ELPM-T2 $\pm 250 \mathrm{~N}$ load cell. The images were recorded at $0.5 \mathrm{~Hz}$ with a Jai TM-4200GE CCD camera using a reduced scan of $2048 \times 1000$ pixels. Figure 1 presents the experimental setup. Simple tensile tests were performed on rectangular samples having an initial gauge length $1_{\circ}=40 \mathrm{~mm}$, width $\mathrm{w}_{\mathrm{o}}=13 \mathrm{~mm}$ and a thickness $\mathrm{e}_{\mathrm{o}}=2 \mathrm{~mm}$. Since the experiment was not intended to fail the specimen, there was no need to use a dumbbell shaped specimen commonly used to prevent specimen failure nearby the clamps. But knowing that the effects of clamps create an indeterminate state of stress and strain in the region surrounding the clamps, due to the process of gripping, the initial gauge length was adopted as being less than the real physical size of the samples. Figure 2 presents the tensile test specimen together with the grid used by the

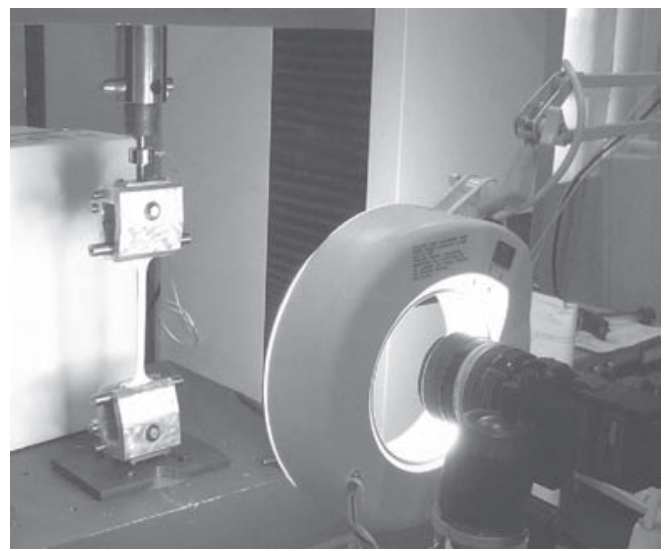

Figure 1. Testing machine with tensile test specimen, load cell and CCD camera.

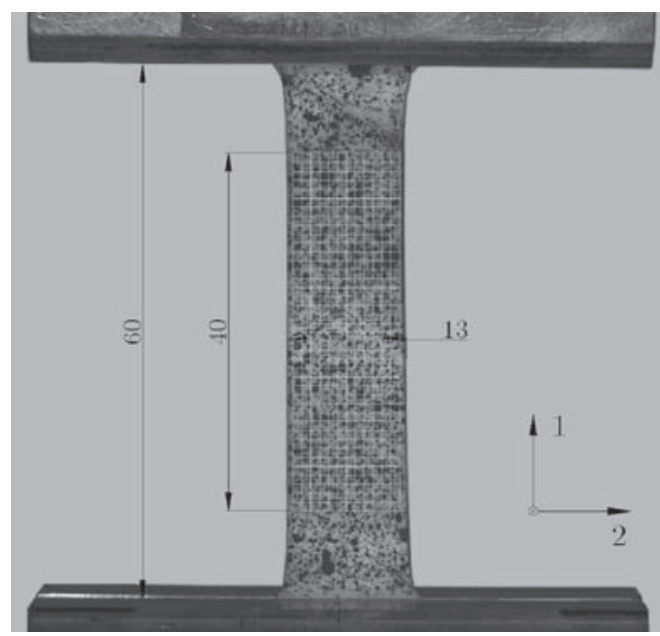

Figure 2. Uniaxial test specimen dimensions and the homogeneous gauge zone.

DIC software to estimate strain fields in the gauge region. For all tests, homogeneity of strain fields in the gauge region has been verified and elongations are averaged values.

\subsection{Strain field measurement}

The DIC technique like a non-contact method is often used to characterize rubber-like materials, see for example Meunier (2008) and Sasso (2008). At each testing time step, one image of the sample deformation was recorded using a CCD camera. The DIC technique allows surface reconstruction of the deformed samples and determination of the full-field surface displacements. For the in-plane 
displacement an accuracy of $10^{-2}$ pixels or better can be reached. For point-to-point strain, the accuracy value lies around $10^{-4}$. The DIC method is preferred because there is no change in sample stiffness resulting from the presence of an attached sensor (classical extensiometry) and for being insensitive to ambient vibrations and rigid body motions (speckle pattern interferometry). Moreover the method is able to deal with high strain levels, what is a very desirable feature given the high strain level experienced by the tested material. Also the DIC allows demonstrating and measuring a heterogeneous deformation field. See Sutton (2008) for further explanation about digital image correlation method.

\section{RESULTS}

\subsection{Simple tensile strain state}

During the test, using an elongation rate of $\lambda^{\prime}=1.60 \times 10^{-2} \mathrm{~s}^{-1}$, the nominal stress tensor $\mathbf{P}$ (First Piola-Kirchhoff stress tensor) is assumed to be homogeneous within the gauge region as well as the deformation gradient tensor $\mathbf{F}$.

Since the actual thickness is not measured, the material is assumed to be incompressible, i.e., $\operatorname{det}(\mathbf{F})=1$ for convenience. In the central zone, the deformation gradient, considering that the direction 1 is the tensile loading one, is given by

$$
\mathbf{F}=\lambda\left(\mathbf{e}_{1} \otimes \mathbf{E}_{1}\right)+\lambda^{-1 / 2}\left(\mathbf{e}_{2} \otimes \mathbf{E}_{2}+\mathbf{e}_{3} \otimes \mathbf{E}_{3}\right)
$$

and the nominal stress tensor

$$
\mathbf{P}=P_{11}\left(\mathrm{e}_{1} \otimes \mathrm{E}_{1}\right)
$$

where $\left(\mathbf{E}_{1}, \mathbf{E}_{2}, \mathbf{E}_{3}\right)$ and $\left(\mathbf{e}_{1}, \mathbf{e}_{2}, \mathbf{e}_{3}\right)$ are the orthonormal basis used for the initial and current configurations, respectively.

In a second time, a tensile specimen has been subjected to a load/unload sequence at different elongation rates $\lambda^{\prime}=25 \times 10^{-4} \mathrm{~s}^{-1}$ to $\lambda^{\prime}=125 \times 10^{-2} \mathrm{~s}^{-1}$ in order to verify the rate-dependence influence. No noticeable difference between stress-strain responses was observed at the considered strain rate range. Consequently the RTV3428 behavior can be assumed independent of the rate of deformation for the observed ranges.

A cyclic tensile loading test was realized, the results are presented in Figure 3. Different phenomena are highlighted, first a large Mullins effect appears by comparing the two first loadings at each strain level, but with very little residual elongation. Moreover, a little hysteresis (difference between second and subsequent loadings and unloadings) is observed.

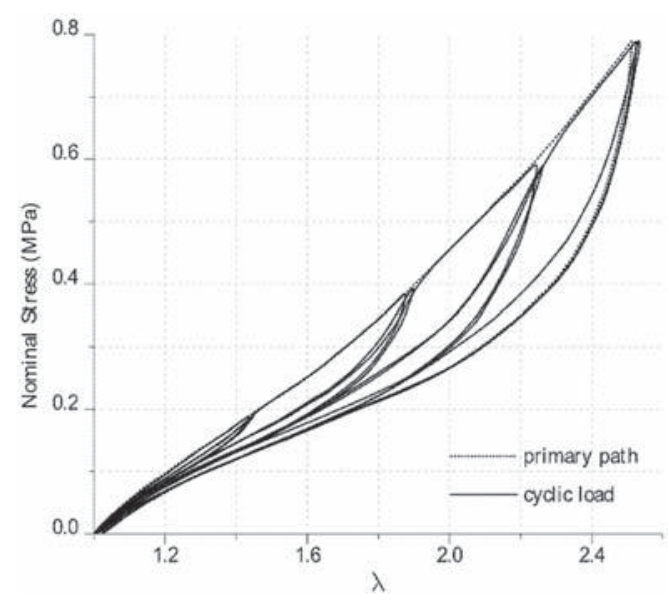

Figure 3. Cyclic loading-unloading tensile test with increasing maximum stress: $0.2,0.4$. 0.6 and $0.8 \mathrm{MPa}$ at $\lambda^{\prime}=1.60 \times 10^{-2} \mathrm{~s}^{-1}$.

\subsection{Directional influence}

Inordertostudy theanisotropyinduced by the Mullins effect, two identical large specimens $1_{\mathrm{o}}=100 \mathrm{~mm}$, width $\mathrm{w}_{\mathrm{o}}=70 \mathrm{~mm}$ and $\mathrm{e}_{\mathrm{o}}=2 \mathrm{~mm}$ of thickness were submitted to one cycle of stretch, at $\lambda=2.45$ in uniaxial tension along a principal direction referred to $0^{\circ}$. Then, a set of smaller specimens was cut from each of these preconditioned large samples along four different directions $0^{\circ}$ (first loading direction), $30^{\circ}, 45^{\circ}$ and $90^{\circ}$ (orthogonal direction). An illustration is presented in Figure 4. All the cut specimens have been submitted to the same initial strain state (this has been verified thanks to the DIC measures). Figure 5 presents the second loading and unloading curves for the different cut specimens.

It clearly appears that all these second loading curves come back on the first loading curve at the same maximum elongation. Moreover, the subsequent unloading curves are almost independent of the history. The main difference is the shape of the second loading curve, the amount of stress-softening can be relied to the angle between the two loading directions.

As represented by Shariff (2006) and Diani (2006b), Figure 6 shows the stress ratio between the first virgin load curve and the set of sub-samples orientated at $0^{\circ}, 30^{\circ}, 45^{\circ}$ and $90^{\circ}$ directions. The curves highlight that there is no proportionality between the different curves, moreover there is no easy link between the second loading curves.

Figure 7 presents the evolution of the loss energy by Mullins effect according to the loading angle. 


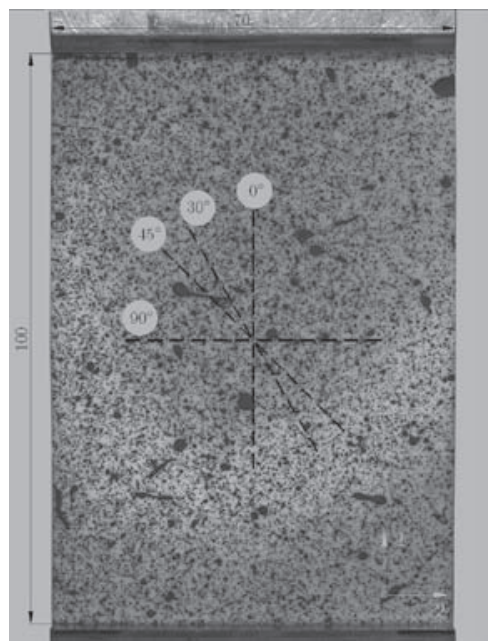

Figure 4. The large preconditioned sample and the different observed orientations.

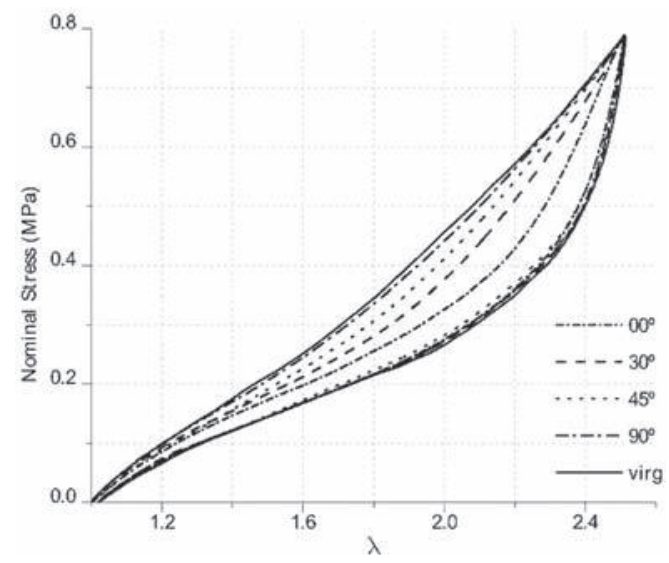

Figure 5. Anisotropy induced by Mullins effect of a filled silicone RTV3428, superposed uniaxial stress-strain responses (load-unload).

Experimental points are fitted using the periodic function given by

$$
W r=\mathrm{a}_{\mathrm{o}}+\mathrm{a}_{1} \cos (\alpha \omega)+\mathrm{a}_{2} \cos (2 \alpha \omega)
$$

where $\mathrm{a}_{\mathrm{o}}=0.460, \mathrm{a}_{1}=0.440, \mathrm{a}_{2}=0.093$ and $\omega=2.0$.

It appears that the function evolves from a maximum of stress-softening, when the two loadings are in the same direction and a minimum, close to zero, when the directions are orthogonal. That means that, at least, two parameters are necessary to describe the Mullins effect: the

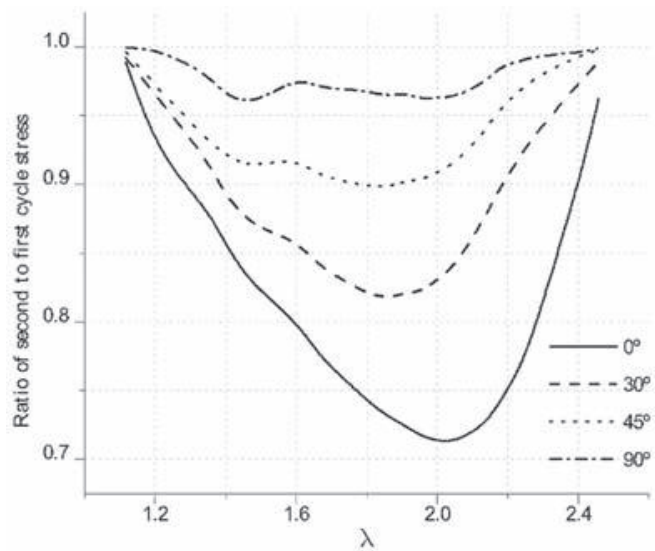

Figure 6. Stress ratio between the first virgin load curve and the set of sub-samples, for sub-samples orientated at $0^{\circ}, 30^{\circ}, 45^{\circ}$ and $90^{\circ}$ (perpendicular) directions.

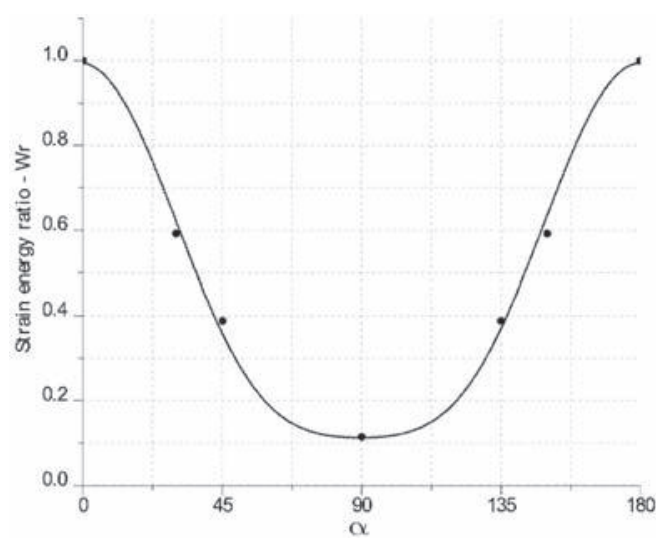

Figure 7. Ratio of energy loss according to the difference of angle loading.

maximum stretch criteria and the angle between the first and second loading.

\section{CONCLUSION}

In the present work we have conducted an experimental campaign to build evidence showing that the Mullins effect in filled silicone rubbers is, in general, non-isotropic. The reproducibility and accuracy of measurements were evaluated through several successive tests. Results have shown that our protocol to manufacture the silicone specimens without any pre-existent anisotropy and our experimental methodology work well and provide a precise experimental characterization of softening phenomena. 
Using the DIC method as a non-contact full-field optical measurement, a large strain level was achieved. The results have shown that tensile cycles in one direction hardly cause any softening in the perpendicular direction. In addition, the results with respect to the influence of Mullins effect in the intermediate directions provide valuable information for testing and calibrating numerical models.

Finally, the anisotropy of the Mullins effect becomes clearly evident and should be taken into account in the constitutive modeling of filled elastomers.

\section{ACKNOWLEDGEMENTS}

We would like to thank the French ANR for supporting this work through the project RAAMO ("Robot Anguille Autonome pour Milieux Opaques").

\section{REFERENCES}

Bergstrom J.S., \& Boyce M.C. 2000. Large strain timedependent behaviour of filled elastomers, Mechanics of Materials, 32(11) pp. 627-644.

Chagnon G., Verron E., Gornet L., Marckmann G., \& CharrierP. 2004. On therelevance of continuum damage mechanics as applied to the Mullins effect in elastomers, J. Mech. Phys. Solids, 52, pp. 1627-1650.

Chagnon G., Verron E., Marckmann G., \& Gornet L. 2006. Development of new constitutive equations for the Mullins effect in rubber using the network alteration theory, Int J Solids Struct, 43, pp. 6817-6831.

Diani J., Brieu M., \& Gilormini P. 2006. Observation and modeling of the anisotropic visco-hyperelastic behaviour of a rubberlike material. Int J Solids Struct, $43-10: 3044-3056$.

Diani J., Brieu M., \& Vacherand J.M. 2006. A damage directional constitutive model for Mullins effect with permanent set and induced anisotropy, European journal of mechanics. A. Solids, 25(3), 483-496.

Itskov M., Haberstroh E., Ehret A.E., \& Vohringer M.C. 2006. Experimental observation of the deformation induced anisotropy of the Mullins effect in rubber,
Kautschuk Gummi Kunststoffe, Volume 59, Issue 3, Pages 93-96.

Laraba-Abbes F., Ienny P., \& Piques R. 2003. A new Taylormade' methodology for the mechanical behaviour analysis of rubberlike materials: II. Application to the hyperelastic behaviour characterization of a carbonblack filled natural rubber vulcanizate. Polymer, 44 (3), 821-840.

Marckmann G., Verron E., Gornet L., ChagnonG., Charrier P., \& Fort P. 2002. A theory of network alteration for the Mullins effect, J. Mech. Phys. Solids, 50, pp. 2011-2028.

Meunier L., Chagnon G., Favier D., Orgeas L., \& Vacher P. 2008. Mechanical experimental characterisation and numerical modelling of an unfilled silicone rubber, Polymer Testing, 27(6), pp. 765-777.

Meunier L., Chagnon G., Favier D., \& Orgeas L. 2008. Experimental and numerical study of the mechanical behaviour of an unfilled silicone rubber, Cosntitutive Models for Rubber V, Pages 35-40.

Miehe C., \& Keck J. 2000. Superimposed finite elastic-viscoelastic-plastoelastic stress response with damage in filled rubbery polymers. Experiments, modelling and algorithmic implementation. J. Mech. Phys. Solids, 48, 323-365.

Muhr A.H., Gough J., \& Gregory I.H. Experimental determination of model for liquid silicone rubber. In: Muhr A, Dorfmann A (eds) Constitutive models for rubber. A.A. Balkema, Rotterdam, pp. 181-187.

Mullins L. 1947. Effect of stretching on the properties of rubber. J. Rubber Res, 16(12), 275-289.

Mullins L. 1969. Softening of rubber by deformation. Rubber Chem. Technol, 42, 339-362.

Pawelski H. Softening behaviour of elastomeric media after loading in changing directions. In: Besdo D, Schuster RH, Ihlemann J (eds) Constitutive models for rubber II. A.A. Balkema Lisse, The Netherlands, pp. 27-36.

Sasso M., Palmieri G., Chiappini G., \& Amodio D. 2008. Characterization of hyperelastic rubber-like materials by biaxial and uniaxial stretching tests based on optical methods. Polymer Testing, 27(8), pp. 995-1004.

Shariff, M.H.B.M. 2006. An anisotropic model of the Mullins effect, Journal of Engineering Mathematics, Springer Netherlands, vol. 56, no. 4, pp. 415-435.

Sutton M.A. 2008. Digital Image Correlation for Shape and Deformation Measurements, Springer Handbook of Experimental Solid Mechanics-PartC, Pages 565-600. 